\title{
In vivo biofilm formation on stainless steel bonded retainers during different oral health-care regimens
}

\begin{abstract}
Marije A Jongsma ${ }^{1}$, Henny C van der Mei $^{2}$, Jelly Atema-Smit ${ }^{2}$, Henk J Busscher ${ }^{2}$ and Yijin Ren ${ }^{1}$
Retention wires permanently bonded to the anterior teeth are used after orthodontic treatment to prevent the teeth from relapsing to pre-treatment positions. A disadvantage of bonded retainers is biofilm accumulation on the wires, which produces a higher incidence of gingival recession, increased pocket depth and bleeding on probing. This study compares in vivo biofilm formation on single-strand and multi-strand retention wires with different oral health-care regimens. Two-centimetre wires were placed in brackets that were bonded to the buccal side of the first molars and second premolars in the upper arches of 22 volunteers. Volunteers used a selected toothpaste with or without the additional use of a mouthrinse containing essential oils. Brushing was performed manually. Regimens were maintained for 1 week, after which the wires were removed and the oral biofilm was collected to quantify the number of organisms and their viability, determine the microbial composition and visualize the bacteria by electron microscopy. A 6-week washout period was employed between regimens. Biofilm formation was reduced on single-strand wires compared with multi-strand wires; bacteria were observed to adhere between the strands. The use of antibacterial toothpastes marginally reduced the amount of biofilm on both wire types, but significantly reduced the viability of the biofilm organisms. Additional use of the mouthrinse did not result in significant changes in biofilm amount or viability. However, major shifts in biofilm composition were induced by combining a stannous fluoride- or triclosan-containing toothpaste with the mouthrinse. These shifts can be tentatively attributed to small changes in bacterial cell surface hydrophobicity after the adsorption of the toothpaste components, which stimulate bacterial adhesion to the hydrophobic oil, as illustrated for a Streptococcus mutans strain. International Journal of Oral Science (2015) 7, 42-48; doi:10.1038/ijos.2014.69; published 9 January 2015
\end{abstract}

Keywords: antimicrobials; biofilm; bonded retention wires; mouthrinse; orthodontics

\section{INTRODUCTION}

A major challenge in orthodontics is the retention of treatment results after the removal of orthodontic appliances. Long-term results of orthodontic treatment indicate a relapse of crowding without the use of retention devices. ${ }^{1}$ To prevent relapse, permanent retention wires are often bonded to the anterior teeth. ${ }^{2}$ Different types of retention wires can be used, including single-strand retainers bonded only to the canines or multi-strand retainers that are bonded to all six anterior teeth. ${ }^{3-4} \mathrm{~A}$ disadvantage of retention wires is the accumulation of biofilm and calculus along the wires, which may cause a higher incidence of gingival recession, increased pocket depth and bleeding on probing. ${ }^{5-6}$

In vitro studies have indicated that wire morphology influences the number of viable organisms in the biofilm on retention wires. ${ }^{7}$ Biofilms pre-formed on single-strand wires yielded less viable organisms than biofilms formed on multi-strand wires after a single exposure to a NaF-sodium lauryl sulphate-containing toothpaste slurry and an essential oil-containing mouthrinse, demonstrating that biofilms on multi-strand wires are less susceptible to oral antimicrobials than biofilms on single-strand wires. The biofilm mode of growth protects its inhabitants against the penetration of antimicrobial agents, ${ }^{8}$ and this effect may be enhanced when the biofilm forms in the crevices and niches of retention wires. ${ }^{9}$ However, it is unclear how these differences in the susceptibility of oral biofilms pre-formed on different wire morphologies in vitro correspond to biofilm formation in vivo during the use of antibacterial health-care products, such as toothpastes or mouthrinses with antibacterial effects.

In most of the population, not all biofilm is removed by mechanical means, and despite the difficulty of antimicrobial penetration of a biofilm, oral antimicrobials generally have a favourable effect on biofilm inhibition in vivo. ${ }^{10-13}$ The biofilm left behind after brushing, both dead and alive, can play an important role in improving antimicrobial action because this biofilm material can absorb antimicrobials, which are then released over time in antimicrobially effective amounts. ${ }^{14}$ However, the clinical relevance of this phenomenon for producing measurable effects on biofilm formation is unclear.

The aim of this study was to compare biofilm formation in vivo on both single-strand and multi-strand retention wires during different oral health-care regimens and to determine whether the use of oral antimicrobials influences biofilm composition. The regimens included manual brushing. Two toothpastes with antibacterial claims ${ }^{15}$ that contained either stannous fluoride or triclosan or a fluoridated toothpaste without antibacterial claims were used. Toothpastes were employed with or without the additional use of a mouthrinse containing essential oils. ${ }^{12}$ 


\section{MATERIALS AND METHODS}

\section{Retainers, volunteers and inclusion criteria}

Two different types of retainers were evaluated in this study, a singlestrand wire (Forestanit ${ }^{\circledR}$; Forestadent, Pforzheim, Germany) and a multi-strand wire (Quadcat ${ }^{\circledR}$; PG Supply, Avon, CT, USA). Brackets (SPEED System Orthodontics, Cambridge, Canada) were bonded to the buccal side of the first molar and the second premolar in the upper arch of 22 healthy volunteers in agreement with the rules set by the Ethics Committee at the University Medical Centre Groningen (letter, 23 June 2011). The length of wire between the brackets was $2 \mathrm{~cm}$. The wires were sterilized in $70 \%$ ethanol before use and were maintained in situ for 1 week, during which the volunteers were instructed to brush for 2 min twice a day with a manual toothbrush (Lactona iQ X-Soft; Lactona Europe B.V., Bergen op Zoom, The Netherlands) and a toothpaste with antibacterial claims (Oral-B Pro Expert ${ }^{\circledR}$; Procter \& Gamble, Cincinnati, OH, USA, or Colgate Total ${ }^{\circledR}$; ColgatePalmolive Company, Piscataway, NJ, USA) or a toothpaste without antibacterial claims that contained only NaF-sodium lauryl sulphate (Prodent Softmint ${ }^{\circledR}$; Sara Lee Household \& Bodycare, Exton, PA, USA). Toothpaste was used either without additional oral hygiene measures or in combination with an essential oil-containing mouthrinse (Cool Mint Listerine ${ }^{\circledR}$; Pfizer Consumer Healthcare, Morris Plains, NJ, USA).

Between regimens, a washout period of 6 weeks was applied during which only the NaF-sodium lauryl sulphate-containing toothpaste without antibacterial claims was used. The duration of the washout period was based on the results of a pilot study that indicated that the composition of the oral biofilm returns to baseline values within 5 weeks after terminating the use of an antibacterial toothpaste.

Volunteers were included in the study if they had healthy and complete dentition, no bleeding upon probing, did not use any medication and did not smoke. All volunteers provided written informed consent. After inclusion, volunteers were randomly assigned to two groups. The first group successively used three different types of toothpaste, and the second group combined the same toothpastes with an antimicrobial mouthrinse (Figure 1).

Regimens were maintained for 1 week, after which the wires were removed and the oral biofilm was collected from the buccal enamel surfaces for reference using a cotton swab. Unstimulated salivary samples were also taken. The wires, collected enamel biofilms and salivary samples were stored in an Eppendorf tube containing $1.0 \mathrm{~mL}$ of filtersterilized reduced transport fluid. ${ }^{16}$ Saliva samples were stored on ice.
To enumerate organisms, retention wires with adherent biofilm and cotton swabs with oral biofilm collected from enamel were both stored in Eppendorf tubes containing $1.0 \mathrm{~mL}$ of filter-sterilized reduced transport fluid; the saliva samples were separately sonicated three times for $10 \mathrm{~s}$ at 30-s intervals in ice-chilled water to disperse the bacteria. The bacteria were then enumerated in a Bürker-Türk counting chamber. In addition, the percentage viability of the biofilms was evaluated after live/dead staining (BacLight ${ }^{\mathrm{TM}}$; Invitrogen, Breda, The Netherlands) of dispersed biofilms. Live/dead stain was prepared by adding $3 \mu \mathrm{L}$ of $\mathrm{SYTO}^{\circledR} 9 /$ propidium iodide $(1: 3)$ to $1 \mathrm{~mL}$ of sterile, demineralized water. Then, $15 \mu \mathrm{L}$ of the stain was added to $10 \mu \mathrm{L}$ of the undiluted biofilm dispersion. After a 15-min incubation in the dark, the numbers of live and dead bacteria were counted using a fluorescence microscope (Leica DM4000B; Leica Microsystems Heidelberg GmbH, Heidelberg, Germany) and expressed as percentage viability. Scanning electron micrographs of the biofilms on wires were acquired as described below.

\section{Denaturing gradient gel electrophoresis analysis of in vivo biofilms} All samples of the in vivo formed biofilms and the saliva were stored at $-80{ }^{\circ} \mathrm{C}$ until comparison of their microbial composition by polymerase chain reaction (PCR)-denaturing gradient gel electrophoresis (DGGE). To extract DNA, the samples were thawed, centrifuged for $5 \mathrm{~min}$ at $13000 \mathrm{~g}$ (Eppendorf Centrifuge 5415D; Eppendorf Instruments, Hamburg, Germany) and subsequently washed and vortexed with $200 \mu \mathrm{L}$ of TE-buffer $\left(10 \mathrm{mmol} \cdot \mathrm{L}^{-1}\right.$ tris(hydroxymethyl)aminomethane (Tris)- $\mathrm{HCl}, 1 \mathrm{mmol} \cdot \mathrm{L}^{-1}$ ethylenediamine tetraacetic acid $\mathrm{pH} 7.4$ ), followed by centrifugation for $5 \mathrm{~min}$ at $13000 \mathrm{~g}$. Next, the supernatant was removed, and the pellet was heated in a microwave (500 W, $5 \mathrm{~min}$ ) and then suspended in $50 \mu \mathrm{L}$ TE-buffer, vortexed and placed on ice. The quality and quantity of the DNA samples were measured using a NanoDrop ${ }^{\circledR}$ spectrophotometer (ND-1000; NanoDrop Technologies, Wilmington, DE, USA) at $230 \mathrm{~nm}$. The final concentration of each DNA sample was adjusted to $100 \mathrm{ng}$ of DNA for PCR amplifications.

PCR was performed with a Tgradient thermocycler (Bio-Rad Icycler; GENOtronics BV, Landgraaf, The Netherlands). To amplify the $16 \mathrm{~S}$ rRNA gene, the following bacterial primers were used: F357GC (forward primer, 5'-GC clamp-TACGGGAGGCAGCAG-3') ${ }^{17}$ containing a GC clamp (5'-CGCCCGCCGCGCCCCGCGCCCGGCCCGCCGCCCCCGCCCC- $\left.3^{\prime}\right)^{18}$ for use in DGGE, and R-518 (reverse primer, 5 -ATTACCGCGGCTGCTGG-3'). ${ }^{19}$ Each $25-\mu \mathrm{L}$ PCR mixture contained $12.5 \mu \mathrm{L}$ of PCR Master Mix (0.05 units per
Group 1

\section{Group 2}

Wash-out, 6 weeks

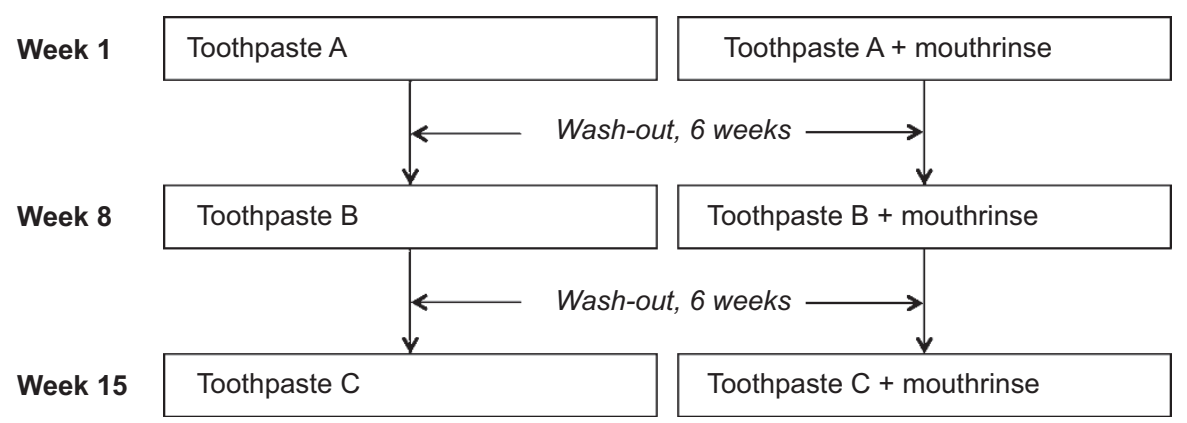

Figure 1 Schematic description of the two experimental groups. Each group consisting of 11 volunteers. Toothpastes were randomly assigned and included the following: toothpaste without antibacterial claims (Prodent Softmint; Sara Lee Household \& Bodycare, Exton, PA, USA); stannous fluoride-containing toothpaste (OralB Pro Expert; Procter \& Gamble, Cincinnati, OH, USA); triclosan-containing toothpaste (Colgate Total; Colgate-Palmolive Company, Piscataway, NJ, USA). The mouthrinse was Cool Mint Listerine ${ }^{\circledR}$ (Pfizer Consumer Healthcare, Morris Plains, NJ, USA). 
$\mu \mathrm{L}$ Taq DNA polymerase in reaction buffer, $4 \mathrm{mmol} \cdot \mathrm{L}^{-1} \mathrm{MgCl}_{2}$, $0.4 \mathrm{mmol} \cdot \mathrm{L}^{-1} \mathrm{dATP}, 0.4 \mathrm{mmol} \cdot \mathrm{L}^{-1} \mathrm{dCTP}, 0.4 \mathrm{mmol} \cdot \mathrm{L}^{-1} \mathrm{dGTP}$, $0.6 \mathrm{mmol} \cdot \mathrm{L}^{-1}$ dTTP (Fermentas Life Sciences, Burlington, ON, Canada)), $1 \mu \mathrm{L}$ each of forward and reverse primers $\left(1 \mu \mathrm{mol} \cdot \mathrm{L}^{-1}\right)$ and $100 \mathrm{ng}$ of DNA (in a volume of $10.5 \mu \mathrm{L}$ ). The temperature profile included an initial denaturing step at $94{ }^{\circ} \mathrm{C}$ for $5 \mathrm{~min}$, followed by a denaturing step at $94{ }^{\circ} \mathrm{C}$ for $45 \mathrm{~s}$, a primer annealing step at $58{ }^{\circ} \mathrm{C}$ for $45 \mathrm{~s}$, an extension step at $72{ }^{\circ} \mathrm{C}$ for $1 \mathrm{~min}$ and a final extension step of $72{ }^{\circ} \mathrm{C}$ for $5 \mathrm{~min}$. PCR products were analysed by electrophoresis on a $2.0 \%$ agarose gel containing $0.5 \mu \mathrm{g} \cdot \mathrm{mL}^{-1}$ ethidium bromide.

DGGE of the PCR products generated with the F357-GC/R-518 primer set was performed as described by Muyzer et al. ${ }^{20}$ using a PhorU system (INGENY, Goes, The Netherlands). The PCR products were applied to an $0.08 \mathrm{~g} \cdot \mathrm{mL}^{-1}$ polyacrylamide gel in $0.5 \times$ TAE buffer $\left(20 \mathrm{mmol} \cdot \mathrm{L}^{-1}\right.$ Tris acetate, $10 \mathrm{mmol} \cdot \mathrm{L}^{-1}$ sodium acetate, $0.5 \mathrm{mmol} \cdot \mathrm{L}^{-1}$ EDTA, pH 8.3). The denaturing gradient consisted of $30 \%-80 \%$ denaturant ( $100 \%$ denaturant equals $7 \mathrm{~mol} \cdot \mathrm{L}^{-1}$ urea and $37 \%$ formamide). Gels were poured using a gradient mixer. A $10-\mathrm{mL}$ stacking gel without denaturant was poured on top. Electrophoresis was performed overnight at $120 \mathrm{~V}$ and $60{ }^{\circ} \mathrm{C}$. Gels were stained with silver nitrate. ${ }^{18}$ Each DGGE gel was normalized to a marker consisting of seven reference bacterial species associated with oral health and disease ${ }^{21}$ and stored at $4{ }^{\circ} \mathrm{C}$. The reference strains included Lactobacillus sp., Streptococcus oralis ATCC 35037, Streptococcus mitis ATCC 9811, Streptococcus sanguinis ATCC 10556, Streptococcus salivarius HB, Streptococcus sobrinus ATCC 33478 and S. mutans ATCC 10449. ${ }^{14}$

\section{Scanning electron microscopy}

Biofilms on the different wires were visualized using scanning electron microscopy (SEM). The wires were fixed overnight in $2 \%$ glutaraldehyde and post-fixed for $1 \mathrm{~h}$ with $1 \%$ osmium tetroxide. After dehydration in a water-ethanol series, the wires were incubated in tetramethylsilane, air-dried and sputter-coated with a gold-palladium alloy, after which they were fixed on SEM-stub-holders using doublesided sticky carbon tape and visualized using a field emission SEM, type $6301 \mathrm{~F}$ (JEOL Ltd, Tokyo, Japan) at $2 \mathrm{kV}$ with a working distance of $39 \mathrm{~mm}$ and a small spot size.

\section{Statistical analysis}

Data were analysed using the Statistical Package for Social Sciences (Version 16.0; SPSS Chicago, IL, USA). One-way analysis of variance was used to compare the number of bacteria and their percentage viability. A Bonferroni test was used for post-hoc multiple comparisons. Statistical significance was set at $P<0.05$.

DGGE gel images were converted and transferred to a microbial database using GelCompar II, version 6.1 (Applied Maths N.V, SintMartens-Latem, Belgium). The similarities in the bacterial compositions of the different biofilms and salivary samples were analysed using a band-based similarity coefficient and a non-weighted pair group method in which arithmetic averages were used to generate dendograms indicating similarities in composition. ${ }^{22}$

\section{RESULTS}

A slightly but significantly higher total number of bacteria were collected from the multi-strand wires compared with the single-strand wires, regardless of the oral health-care regimen applied $(P<0.01$, Table 1). The percentage viability of the bacteria adhering to the different types of wires was significantly higher for single-strand wires compared with multi-strand wires $(P<0.05)$ and buccal enamel surfaces $(P<0.001)$ when using a standard, fluoridated toothpaste without antibacterial claims, independent of the additional use of an essential oil-containing mouthrinse.

The use of antibacterial toothpastes without the mouthrinse had little effect on the total number of bacteria retrieved from the wires but significantly reduced their viability $(P<0.001)$. The viability remained higher on the wires than on the buccal enamel surfaces. The use of a triclosan-containing toothpaste with the mouthrinse yielded the lowest number and viability of adhering bacteria on either wire.

The microbial compositions of the biofilms adhering to the different wires and buccal enamel surfaces and of the salivary microbiome were compared using a cluster tree (Figure 2a) combining the different oral hygiene regimens. The composition of the salivary microbiome was distinct from that of the different adhering biofilms, with a higher prevalence of $S$. salivarius and a lower prevalence of $S$. mutans (Table 2). Biofilms adhering to the wires had a higher prevalence of

Table 1 The number and viability of bacteria retrieved from 1-cm retainer wires treated with the different toothpastes alone or in combination with the essential oil-containing mouthrinse

\begin{tabular}{|c|c|c|c|c|c|}
\hline \multirow[b]{2}{*}{ Treatments } & \multicolumn{2}{|c|}{ Number of bacteria (log-units) } & \multicolumn{3}{|c|}{ Live bacteria/\% } \\
\hline & Single-strand & Multi-strand & Single-strand & Multi-strand & Enamel \\
\hline $\begin{array}{l}\text { Toothpaste without antibacterial } \\
\text { claims }\end{array}$ & $7.5 \pm 0.2^{a}$ & $8.0 \pm 0.2$ & $68 \pm 10^{a, d}$ & $51 \pm 19$ & $38 \pm 14$ \\
\hline $\begin{array}{l}\text { Toothpaste without antibacterial } \\
\text { claims + mouthrinse }\end{array}$ & $7.2 \pm 0.2^{\mathrm{a}}$ & $7.8 \pm 0.2$ & $78 \pm 8^{a, d}$ & $57 \pm 12$ & $46 \pm 11$ \\
\hline $\begin{array}{l}\text { Stannous fluoride-containing } \\
\text { toothpaste }\end{array}$ & $7.3 \pm 0.1^{a}$ & $7.8 \pm 0.3$ & $25 \pm 8^{e}$ & $36 \pm 10^{e}$ & $20 \pm 12^{e}$ \\
\hline $\begin{array}{l}\text { Stannous fluoride-containing } \\
\text { toothpaste + mouthrinse }\end{array}$ & $7.0 \pm 0.1^{a, b}$ & $7.5 \pm 0.3^{b}$ & $24 \pm 10^{e}$ & $32 \pm 11^{\mathrm{e}}$ & $22 \pm 10^{e}$ \\
\hline Triclosan-containing toothpaste & $7.1 \pm 0.2^{a, b}$ & $7.7 \pm 0.3^{b}$ & $27 \pm 8^{e}$ & $30 \pm 4^{e}$ & $17 \pm 8^{\mathrm{e}}$ \\
\hline $\begin{array}{l}\text { Triclosan-containing } \\
\text { toothpaste+mouthrinse }\end{array}$ & $6.6 \pm 0.2^{a, b, c}$ & $7.4 \pm 0.2^{b}$ & $23 \pm 7^{e}$ & $28 \pm 4^{e}$ & $19 \pm 4^{e}$ \\
\hline
\end{tabular}

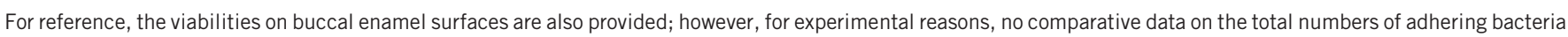
are provided. All data are expressed as averages \pm standard deviations over 11 different volunteers.

a Significantly different from multi-strand wire.

${ }^{\text {b }}$ Significantly different from a toothpaste without antibacterial claims.

${ }^{c}$ Significantly different from toothpaste only.

d Significantly different from enamel.

e Significantly different from a toothpaste without antibacterial claims, with or without the use of mouthrinse. 
a

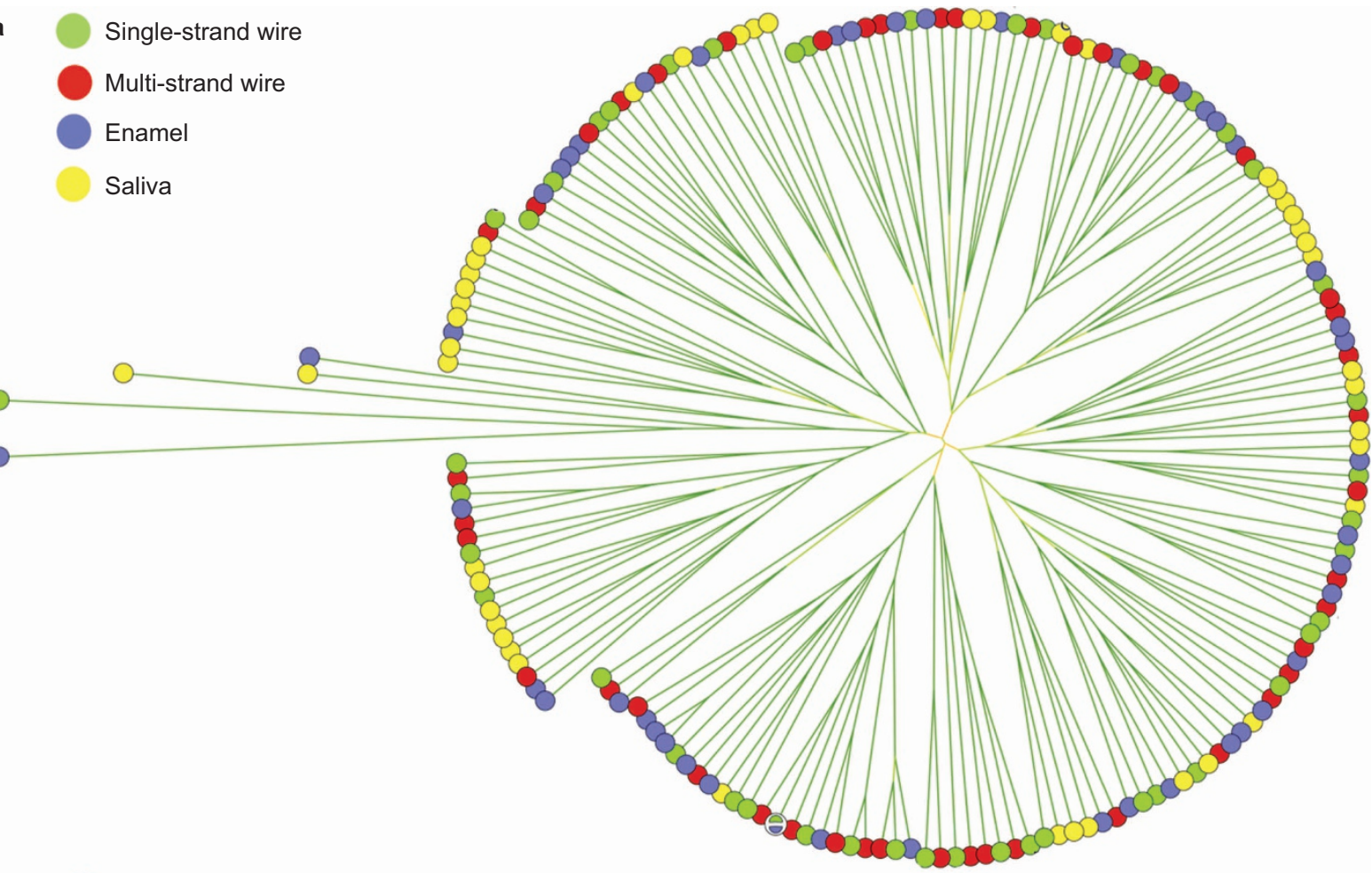

b

Toothpaste without antibacterial claims

Stannous fluoride containang toothpaste

Triclosan containing toothopaste

Toothpaste without antibacterial claims + mouthrinse

Stannous fluoride containing toothpaste + mouthrinse

Tricosan containing toothpaste + mouthrinse

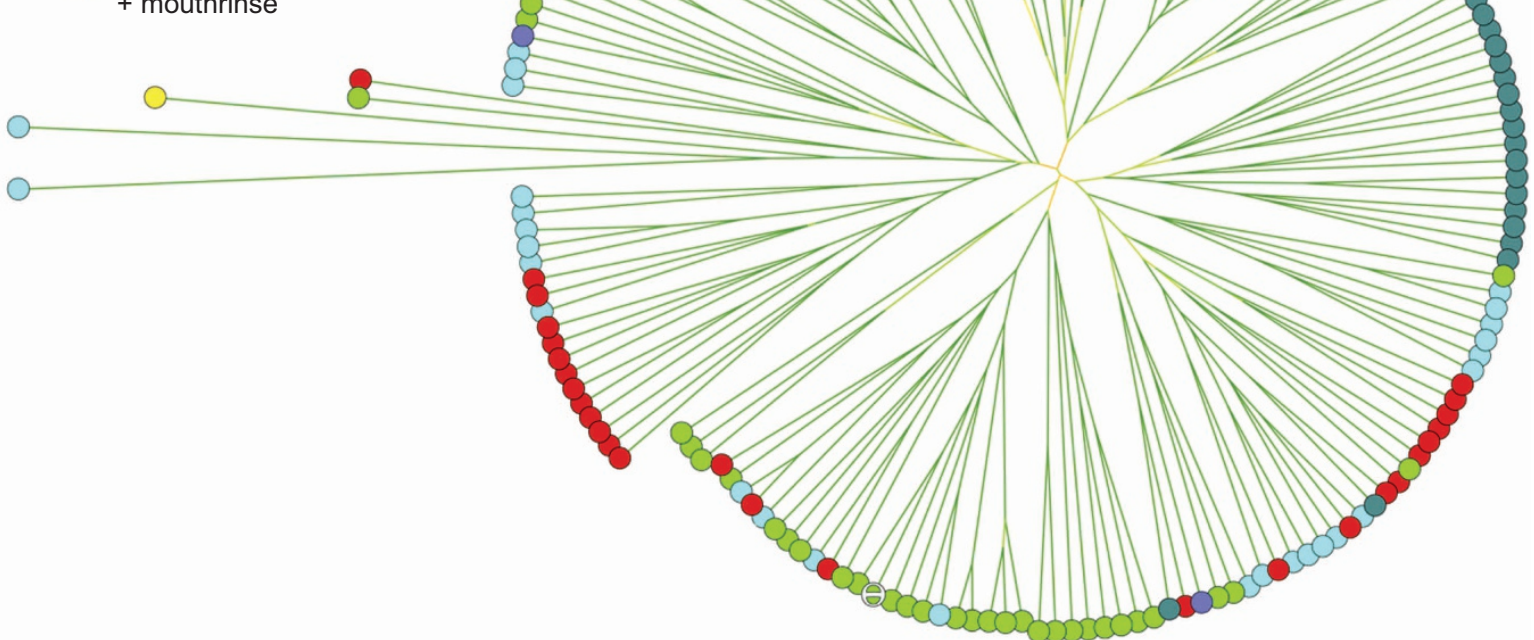

Figure 2 Clustering trees describing the bacterial compositions of the microbial samples taken from the different volunteers in this study. The corresponding circles in $\mathbf{a}$ and $\mathbf{b}$ represent the same sample. (a) Colours indicate different locations of microbial sampling, i.e., enamel, retention wires or saliva. (b) Colours indicate the use of different oral health-care regimens. 

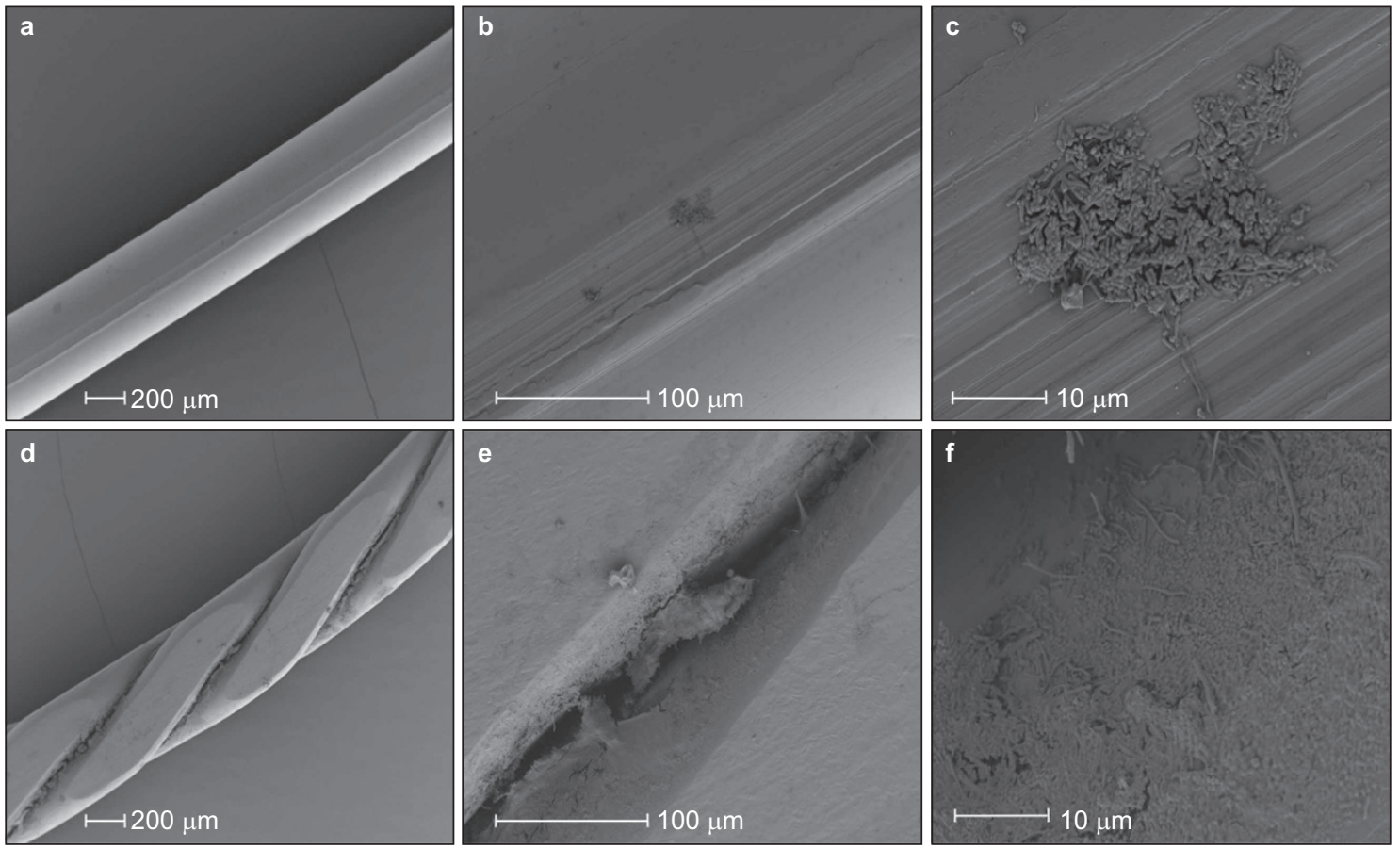

Figure 3 Scanning electron micrographs of 1-week-old biofilms formed in vivo during use of a toothpaste without antibacterial claims. (a-c) Single-strand wire. (d-f) Multi-strand wire.

Lactobacilli and S. sobrinus than biofilms adhering to the buccal enamel surfaces (Table 2).

Combining the results for the different biofilms revealed an influence of the oral health-care regimen (Figure 2b). Regimens involving only the triclosan-containing toothpaste and regimens involving the use of the different individual toothpastes in combination with the mouthrinse formed clear clusters. The regimen involving only the stannous fluoride toothpaste yielded a decrease in the prevalence of lactobacilli, S. oralis/S. mitis and S. sanguinis compared with the toothpaste without antibacterial claims, and this decrease continued when the stannous fluoride-containing paste was used with the mouthrinse. In the latter combined regime,
S. salivarius was also less prevalent (Table 2). The prevalence of S. sobrinus and S. mutans in the biofilms adhering to the wires and buccal enamel surfaces was not affected by the combined use of toothpaste without antibacterial claims and mouthrinse compared to toothpaste alone. The triclosan-containing toothpaste produced major increases in the prevalence of adherent S. oralis/S. mitis, S. sanguinis and S. mutans. However, the combination of the triclosan-containing toothpaste with the essential oil-containing mouthrinse resulted in the lowest prevalence of Lactobacilli, S. sobrinus and S. mutans among the different regimens.

Scanning electron micrographs (Figure 3 ) revealed the protected location of bacteria adhering to multi-strand wires. On the

Table 2 Prevalence of marker strains in microbial samples from biofilms adhering to the different wires and buccal enamel surfaces and in the salivary microbiome for different oral health-care regimens

\begin{tabular}{|c|c|c|c|c|}
\hline \multirow[b]{2}{*}{ Strains } & \multicolumn{4}{|c|}{ Combining oral health-care regimens } \\
\hline & Single-strand wire & Multi-strand wire & Enamel & Saliva \\
\hline Lactobacillus & 20 & 25 & 13 & 22 \\
\hline S. oralis/mitis & 55 & 56 & 57 & 65 \\
\hline S. sanguinis & 63 & 60 & 65 & 57 \\
\hline S. salivarius & 16 & 21 & 20 & 57 \\
\hline S. sobrinus & 45 & 52 & 39 & 46 \\
\hline S. mutans & 57 & 48 & 57 & 35 \\
\hline
\end{tabular}

\begin{tabular}{|c|c|c|c|c|c|c|}
\hline \multirow[b]{2}{*}{ Strains } & \multicolumn{6}{|c|}{ Combining biofilms adhering to wires and buccal enamel surfaces } \\
\hline & $\begin{array}{l}\text { Toothpaste without } \\
\text { antibacterial claims }\end{array}$ & $\begin{array}{l}\text { Toothpaste without } \\
\text { antibacterial } \\
\text { claims + mouthrinse }\end{array}$ & $\begin{array}{l}\text { Stannous fluoride- } \\
\text { containing toothpaste }\end{array}$ & $\begin{array}{c}\text { Stannous fluoride- } \\
\text { containing } \\
\text { toothpaste + mouthrinse }\end{array}$ & $\begin{array}{l}\text { Triclosan-containing } \\
\text { toothpaste }\end{array}$ & $\begin{array}{l}\text { Triclosan-containing } \\
\text { toothpaste+ mouthrinse }\end{array}$ \\
\hline Lactobacillus & 30 & 45 & 21 & 5 & 11 & 5 \\
\hline S. oralis/mitis & 53 & 95 & 29 & 20 & 86 & 71 \\
\hline S. sanguinis & 67 & 45 & 50 & 10 & 82 & 95 \\
\hline S. salivarius & 23 & 35 & 31 & 10 & 32 & 38 \\
\hline S. sobrinus & 39 & 80 & 43 & 70 & 34 & 33 \\
\hline S. mutans & 30 & 70 & 43 & 85 & 68 & 5 \\
\hline
\end{tabular}

$100 \%$ indicates that all biofilm samples taken from a given volunteer, wire, enamel or saliva contain the indicated marker strain. 
multi-strand wires, the bacteria were mostly located in the crevices between strands, whereas on the single-strand wires, the bacteria were present as a thin scattered film, attached mainly to irregularities on the wire surface.

\section{DISCUSSION}

Biofilm formation in vivo on both single-strand and multi-strand retention wires during the use of antibacterial toothpastes and a mouthrinse was evaluated. Although statistically significant differences in the numbers of bacteria adhering to the retention wires were observed for the use of different toothpastes with and without antibacterial claims alone or in combination with an essential oil-containing mouthrinse, these differences are likely too small to be of clinical significance. These results are consistent with the results of clinical studies showing that antibacterial toothpastes, including the two included in this study, reduce oral biofilm formation. ${ }^{23-24}$ Clinical studies have also confirmed little to no effect of the additional use of an essential oil-containing mouthrinse on oral biofilm formation. ${ }^{12,25-26}$ More interestingly from a clinical perspective, the use of antibacterial toothpastes reduced the percentage viability of the adhering organisms. Statistically significant but likely clinically irrelevant differences in the number of bacteria adhering to single- and multi-strand wires were also observed, but more importantly, the antibacterial regimens caused a more substantial decrease in the viability of the adhering organisms on single-strand wires compared with multi-strand wires, indicating better penetration of antimicrobials into biofilms that form on single-strand wires. These results are consistent with the higher viability of biofilms that form on single-strand wires compared with multi-strand wires during the use of a toothpaste without antibacterial claims. This increased viability is most likely due to the improved access to nutrients of bacteria adhering to single-strand wires compared with multi-strand wires. ${ }^{27}$

The biofilms on both types of retention wires had approximately the same microbial composition (Table 2), with some differences in the composition of the oral biofilm on enamel surfaces. The composition of adhering biofilms is very different from that of the salivary microbiome. These substratum-dependent microbial compositions confirm recent work ${ }^{28}$ that the surface dictates the composition of the biofilm it attracts through differential adhesion forces exerted on different strains of bacteria. The largest differences in microbial composition in biofilms adhering to retention wires and enamel surfaces were observed after regimens of antibacterial toothpastes combined with the essential oil-containing rinse. Most strikingly and of clinical importance, a regimen comprising a triclosan-containing toothpaste complemented with an essential oil-containing mouthrinse yielded a reduction in the prevalence of S. mutans from 30\% to 5\%. Other combination regimens increased the prevalence of $S$. mutans in retainer biofilms. This drastic shift in the composition of the oral microbiome in a less-cariogenic direction, i.e., less S. mutans, by the combination of a triclosan-containing toothpaste with an essential oilcontaining mouthrinse is intriguing. Oil-containing mouthrinses remove bacteria from the oral cavity through bacterial adhesion to the hydrophobic oil, which requires a certain degree of hydrophobicity of the bacterial cell surface. ${ }^{29}$ Moreover, certain concentrations of cationic antibacterial agents, such as cetylpyridinium chloride and chlorhexidine, promote the binding of oral microorganisms to oil droplets. $^{30}$

Hypothetically, exposure to the non-polar triclosan ${ }^{31}$ could increase the hydrophobicity of the $S$. mutans cell surface, which would facilitate the removal of $S$. mutans by hydrophobic oils. To verify this hypothesis, we exposed the $S$. mutans strain used in this study to supernatants of the different toothpastes and examined its removal by a hexadecane in the so-called kinetic MATH assay, ${ }^{32}$ as described in Supplementary Information. The removal rate of $S$. mutans by hexadecane was low (Supplementary Figure S1), classifying the surface of $S$. mutans as slightly hydrophilic (Supplementary Table S1). Only exposure to the triclosan-containing toothpaste supernatant increased the removal of $S$. mutans by hexadecane (see also Supplementary Figure S1 and Supplementary Table S1). This finding supports our hypothesis that exposure to triclosan can increase the hydrophobicity of the $S$. mutans cell surface, facilitating its removal by oil-containing mouthrinses, and corresponds with the observation that $S$. mutans strains grown in the presence of triclosan form more extensive biofilms. ${ }^{33}$ However, the authors of the latter paper ruled out the effects of triclosan on streptococcal cell surface hydrophobicity, most likely because they did not use the MATH assay in its more sensitive kinetic mode as advocated by Lichtenberg et al. ${ }^{32}$ Methods of influencing the composition of oral biofilms towards a 'healthy' composition are in the preliminary stages of development. The adsorption of toothpaste components to increase the hydrophobicity of the surfaces of selected oral pathogens and the use of hydrophobic oil-containing mouthrinses for the subsequent removal of these pathogens from the oral cavity seem to be a clinically feasible approach. The present results warrant more research into components that alter the cell surface hydrophobicity of selected oral bacterial strains.

Whether the compositional changes observed have any beneficial clinical effect remains unclear. However, the use of an antibacterial toothpaste containing sodium lauryl sulphate and stannous fluoride or triclosan increases the $\mathrm{pH}$ of oral biofilms and decreases their viability, ${ }^{34-35}$ resulting in a less cariogenic biofilm. Clearly, such changes in biofilm properties may be considered an indication of an altered microbial composition if not of a reduced prevalence of S. mutans and Lactobacilli in the biofilm. Most studies on oral biofilm composition have employed a control regimen, such as the use of a NaF-sodium lauryl sulphate-containing toothpaste with mint flavour in our study. This paste was chosen as a control because it has no antimicrobial claims; however, potential effects of this toothpaste on oral biofilm viability and composition cannot be ruled out. Both fluoride and sodium lauryl sulphate as well as mint flavouring agents have antibacterial properties, ${ }^{15,36-37}$ and fluoride inhibits calcium-bridging between co-adhering pairs of oral bacteria. $^{38}$

In summary, in vivo, slightly less oral biofilm is formed on singlestrand retention wires compared with multi-strand wires. Orthodontic patients with a fixed bonded retainer would benefit from the use of an appropriate regimen of an antibacterial toothpaste and mouthrinse based on a reduction of biofilm viability rather than biofilm formation. Appropriate regimens may increase the hydrophobicity of selected members of the oral microbiome through the adsorption of non-polar components from toothpastes to subsequently enhance their removal by oil-containing mouthrinses, resulting in less pathogenic biofilms. However, this pathway to restoring a healthy oral microbiome requires further exploration.

\section{CONFLICTS OF INTERESTS}

The authors declare no potential conflicts of interest with respect to authorship and/or publication of this article. The opinions and assertions contained herein are those of the authors and do not necessarily represent the views of the companies that donated the various wires or their respective employees. 


\section{ACKNOWLEDGEMENTS}

This study was entirely funded by the University Medical Centre Groningen, Groningen, The Netherlands. The authors would like to extend their gratitude to the volunteers who participated in the study and to Mr Jeroen Kuipers from the Centre for Medical Electron Microscopy of the University Medical Centre Groningen for his assistance with the SEM analysis, Dentsply Lomberg (Soest, The Netherlands) and Orthotec B.V. (Zeist, The Netherlands) for kindly providing the various wires used in this study. Henk J Busscher is also the director of a consulting company, SASA BV, Thesinge, The Netherlands. Publication of this manuscript is supported by Open Fund of State Key Laboratory of Oral Diseases, Sichuan University.

1 Little RM. Stability and relapse of mandibular anterior alignment: University of Washington studies. Semin Orthod 1999; 5(3): 191-204.

2 Renkema AM, Sips ET, Bronkhorst E et al. A survey on orthodontic retention procedures in The Netherlands. Eur J Orthod 2009; 31(4): 432-437.

3 Renkema AM, Al-Assad S, Bronkhorst E et al. Effectiveness of lingual retainers bonded to the canines in preventing mandibular incisor relapse. Am J Orthod Dentofacial Orthop 2008; 134(2): 179e1-179e8.

4 Renkema AM, Renkema A, Bronkhorst E et al. Long-term effectiveness of canine-tocanine bonded flexible spiral wire lingual retainers. Am J Orthod Dentofacial Orthop $2011 ;$ 139(5): 614-621.

5 Pandis N, Vlahopoulos K, Madianos $\mathrm{P}$ et al. Long-term periodontal status of patients with mandibular lingual fixed retention. Eur J Orthod 2007; 29(5): 471-476.

6 Levin L, Samorodnitzky-Naveh GR, Machtei EE. The association of orthodontic treatment and fixed retainers with gingival health. J Periodontol 2008; 79(11): 2087-2092.

7 Jongsma MA, Pelser FD, van der Mei HC et al. Biofilm formation on stainless steel and gold wires for bonded retainers in vitro and in vivo and their susceptibility to oral antimicrobials. Clin Oral Investig 2013; 17(4): 1209-1218.

8 Flemming HC, Wingender J. The biofilm matrix. Nat Rev Microbio/ 2010; 8(9): 623633.

9 Al-Nimri K, Al Habashneh R, Obeidat M. Gingival health and relapse tendency: a prospective study of two types of lower fixed retainers. Aust Orthod J 2009; 25(2): 142-146.

10 Riep BG, Bernimoulin JP, Barnett ML. Comparative antiplaque effectiveness of an essential oil and an amine fluoride/stannous fluoride mouthrinse. J Clin Periodontol 1999; 26(3): 164-168.

11 Arweiler NB, Auschill TM, Reich E et al. Substantivity of toothpaste slurries and their effect on reestablishment of the dental biofilm. J Clin Periodontol 2002; 29(7): 615621.

12 Stoeken JE, Paraskevas S, van der Weijden GA. The long-term effect of a mouthrinse containing essential oils on dental plaque and gingivitis: a systematic review. J Periodontol 2007; 78(7): 1218-1228.

13 Pizzo G, La Cara M, Licata ME et al. The effects of an essential oil and an amine fluoride/stannous fluoride mouthrinse on supragingival plaque regrowth. J Periodontol 2008; 79(7): 1177-1183.

14 Otten MP, Busscher HJ, Abbas F et al. Plaque-left-behind after brushing: intra-oral reservoir for antibacterial toothpaste ingredients. Clin Oral Investig 2012; 16(5): 1435-1442.

15 Addy M, Moran J. Chemical supragingival plaque control//Lang NP, Lidhe J eds. Clinical periodontology and implant dentistry. Vol. 2. Oxford: Blackwell Munksgaard, 2008: 734-765.

16 Syed SA, Loesche WJ. Survival of human dental plaque flora in various transport media. Appl Microbiol 1972; 24(4): 638-644.

17 Di Cagno R, Rizzello CG, Gagliardi F et al. Different fecal microbiotas and volatile organic compounds in treated and untreated children with celiac disease. Appl Environ Microbiol 2009; 75(12): 3963-3971.
18 Zijnge V, Welling GW, Degener JE et al. Denaturing gradient gel electrophoresis as a diagnostic tool in periodontal microbiology. J Clin Microbiol 2006; 44(10): 36283633.

19 Marsh PD. Microbial ecology of dental plaque and its significance in health and disease. Adv Dent Res 1994; 8(2): 263-271.

20 Muyzer G, de Waal EC, Uitterlinden AG. Profiling of complex microbial populations by denaturing gradient gel electrophoresis analysis of polymerase chain reactionamplified genes coding for 16S rRNA. Appl Environ Microbiol 1993; 59(3): 695700.

21 Marsh PD. Dental plaque as a biofilm and a microbial community -implications for health and disease. BMC Oral Health 2006; 6(Suppl 1): S14.

22 Signoretto $\mathrm{C}$, Bianchi F, Burlacchini $\mathrm{G}$ et al. Drinking habits are associated with changes in the dental plaque microbial community. J Clin Microbiol 2010; 48(2): 347-356.

23 Riley P, Lamont T. Triclosan/copolymer containing toothpastes for oral health. Cochrane Database Syst Rev 2013; (12): CD010514.

$24 \mathrm{He}$ T, Barker ML, Biesbrock A et al. Evaluation of anti-gingivitis benefits of stannous fluoride dentifrice among triclosan dentifrice users. Am J Dent 2013; 26(4): 175179.

25 Cortelli SC, Cortelli JR, Shang H et al. Long-term management of plaque and gingivitis using an alcohol-free essential oil containing mouthrinse: a 6-month randomized clinical trial. Am J Dent 2013; 26(3): 149-155.

26 Tufekci E, Casagrande ZA, Lindauer SJ et al. Effectiveness of an essential oil mouthrinse in improving oral health in orthodontic patients. Angle Orthod 2008; 78(2): 294-298.

27 Sjollema J, Rustema-Abbing M, van der Mei HC et al. Generalized relationship between numbers of bacteria and their viability in biofilms. Appl Environ Microbiol 2011; 77(14): 5027-5029.

28 Wessel SW, Chen Y, Maitra A et al. Adhesion forces and composition of planktonic and adhering oral microbiomes. J Dent Res 2014; 93(1): 84-88.

29 Rosenberg M, Barki M, Bar-Ness R et al. Microbial adhesion to hydrocarbons (math). Biofouling 1991; 4(1/2/3): 121-128.

30 Goldberg S, Rosenberg M. Bacterial desorption by commercial mouthwashes vs twophase oil: Water formulations. Biofouling 1991; 3(3): 193-198.

31 Ellison ML, Champlin FR. Outer membrane permeability for nonpolar antimicrobial agents underlies extreme susceptibility of Pasteurella multocida to the hydrophobic biocide triclosan. Vet Microbiol 2007; 124(3/4): 310-318.

32 Lichtenberg D, Rosenberg M, Sharfman N et al. A kinetic approach to bacterial adherence to hydrocarbon. J Microbiol Methods 1985; 4(3/4): 141-146.

33 Bedran TB, Grignon L, Spolidorio DP et al. Subinhibitory concentrations of triclosan promote Streptococcus mutans biofilm formation and adherence to oral epithelial cells. PLoS One 2014; 9(2): e89059.

34 Kasturi R, White DJ, Lanzalaco AC et al. Effects of nine weeks' use of a new stabilized stannous fluoride dentifrice on intrinsic plaque virulence expressed as acidogenicity and regrowth: a modified PGRM study. J Clin Dent 1995; 6(Spec No): 71-79.

35 Kraivaphan $\mathrm{P}$, Amornchat $\mathrm{C}$, Triratana T. Determination of plaque viability following a single brushing with commercial toothpastes. J Clin Dent 2013; 24(1): 2024.

36 Takahashi N, Washio J. Metabolomic effects of xylitol and fluoride on plaque biofilm in vivo. J Dent Res 2011; 90(12): 1463-1468.

37 Kamatou GP, Vermaak I, Viljoen AM et al. Menthol: a simple monoterpene with remarkable biological properties. Phytochemistry 2013; 96: 15-25.

38 Rose RK, Shellis RP, Lee AR. The role of cation bridging in microbial fluoride binding. Caries Res 1996; 30(6): 458-464.

c) (i)

This work is licensed under a Creative Commons Attribution 3.0 Unported License. The images or other third party material in this article are included in the article's Creative Commons license, unless indicated otherwise in the credit line; if the material is not included under the Creative Commons license, users will need to obtain permission from the license holder to reproduce the material. To view a copy of this license, visit http://creativecommons.org/licenses/by/3.0/ 